Laser Chem. Vol. 7, pp. 343-351

Photocopying permitted by license only

C 1987 Harwood Academic Publishers GmbH

Printed in the United Kingdom

\title{
Bridged Quaterphenyls as Flashlamp-Pumpable Laser Dyes
}

\author{
JOEL M. KAUFFMAN* CHARLES J. KELLEY‡, \\ ALEM GHIORGHIS $¥$, EDWARD NEISTER§, LORNE ARMSTRONG§ \\ and PAUL R. PRAUSE§ \\ * Chemistry Department, Philadelphia College of Pharmacy and Science, \\ 43rd Street and Kingsessing Mall, Phila., PA 19104, USA \\ $¥$ Chemistry Department, Massachusetts College of Pharmacy and A.H.S., \\ 179 Longwood Ave., Boston, MA 02115, USA \\ §Phase-R Corp., Old Bay Rd, New Durham, NH 03855, USA
}

(Received 22 January 1987; in revised form 18 February 1987)

Partial bridging of the $0, \mathrm{o}^{\prime}$ positions of the aromatic rings in quaterphenyl gave superior flashlamp-pumpable laser dyes. Alkyl-substituted carbon bridges gave superior dyes to those containing oxygen or alkyl-substituted nitrogen or silicon bridges. Dyes lasing in the 365-390 $\mathrm{nm}$ region with improved energy output, lifetime and solubility were discovered.

KEY WORDS: Laser dyes, flashlamp pumped, ultraviolet, quaterphenyls

\section{INTRODUCTION}

Oligophenylenes such as quaterphenyls have been among the most successful laser dyes in the ultraviolet region of the spectrum, ${ }^{1}$ especially dye 1 (Figure 1). Their lack of solubility, especially in polar non-toxic solvents (Table I), has severely limited their use. ${ }^{2}$ Attempts to place substituents on the internal ortho positions of the aromatic rings improved the solubility, but reduced both the fluorescence quantum yield (FQE) and the conversion efficiency. ${ }^{3,4}$ Sulfonation of quaterphenyl produced a dye, "polyphenyl 1 ," which was soluble only in viscous solvents, and apparently suitable only for low power outputs. ${ }^{5}$ 
DveNo. $\frac{\text { Nome }}{1 \quad \begin{array}{c}4,4 \cdots-\text { bis( 2-butyloctyloxy)- } \\ \text {-quaterphenyl }\end{array}}$

2 2,2'-bifluorene

3 3,3'-bi(dibenzofuran)
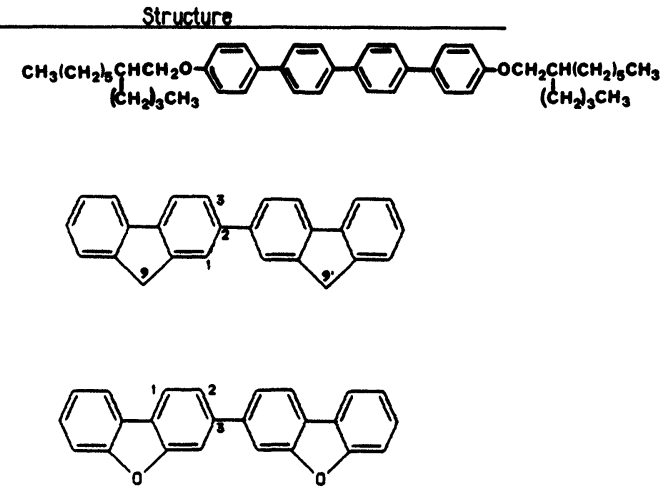

4 9,9'-diethyl-2,2'- bicarbazole

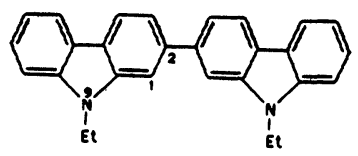

5 2,7-diphenyl-9,9-dipropyl-fluorene

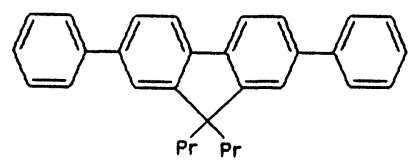

$6 \quad 9,9,9^{\prime}, 9^{\prime}$-tetrapropyl-2,2' -bifluorene

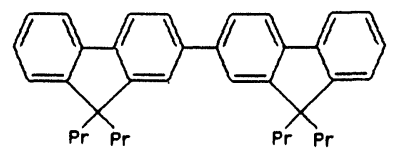

7 2,7-bis( 4-methoxyphenyl)-9,9-dipropylfluorene

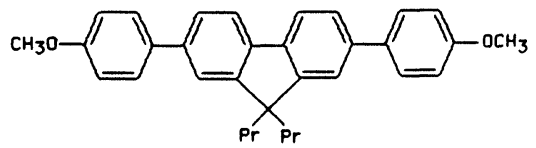

8 2,7-bis(6-chromanyl)-9,9-dipropylfluorene

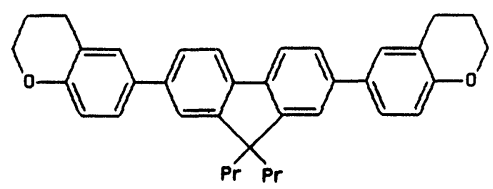

Figure 1 Names and structures of quaterphenyl dyes tested. 
Placement of other solubility-promoting groups on the meta and para positions of the outer phenyl group had little effect on solubility unless the groups were large, as in the most successful ultraviolet-emitting dye in current use, dye 1 in Figure $1 .^{6}$

Table I Solubilities of quaterphenyl dyes tested (in moles/liter)

\begin{tabular}{llllll}
\hline Dye No. & Cyclohexane & DMF $^{\mathrm{a}}$ & DMA $^{\mathrm{b}}$ & Ethanol & Methanol \\
\hline 1 & - & $1.0 \times 10^{-3}$ & - & $2.3 \times 10^{-5}$ & $2.6 \times 10^{-6}$ \\
2 & $3.0 \times 10^{-5}$ & $1.0 \times 10^{-3}$ & - & $2.3 \times 10^{-5}$ & - \\
3 & $9.0 \times 10^{-5}$ & $2.5 \times 10^{-3}$ & - & $6.3 \times 10^{-5}$ & $2.1 \times 10^{-5}$ \\
4 & $9.4 \times 10^{-5}$ & $1.1 \times 10^{-2}$ & - & $2.5 \times 10^{-5}$ & - \\
5 & - & $1.1 \times 10^{-2}$ & $1.3 \times 10^{-2}$ & $1.3 \times 10^{-3}$ & $5.8 \times 10^{-4}$ \\
6 & $2.0 \times 10^{-2}$ & $9.3 \times 10^{-3}$ & $7.3 \times 10^{-3}$ & $7.8 \times 10^{-4}$ & $3.4 \times 10^{-4}$ \\
7 & $>10^{-3}$ & $1.7 \times 10^{-2}$ & $2.0 \times 10^{-2}$ & $6.4 \times 10^{-4}$ & $4.4 \times 10^{-4}$ \\
8 & $>10^{-3}$ & $3.3 \times 10^{-3}$ & $5.0 \times 10^{-3}$ & $3.4 \times 10^{-4}$ & $3.0 \times 10^{-4}$ \\
\hline
\end{tabular}

${ }^{a} \mathrm{~N}, \mathrm{~N}$-dimethylformamide

b $\mathrm{N}, \mathrm{N}$-dimethylacetamide

Barnett et $a l^{7}$ showed that the $0, \mathrm{o}^{\prime}$ methylene-bridged quaterphenyls 2,2'-bifluorene (2) and 2,7-diphenylfluorene (dye 5 without propyl groups) gave superior pulse heights to that of quaterphenyl in liquid scintillation counting, a process related to lasing at least in that the $S_{1}-S_{0}$ transition of the fluor or dye occurs mainly by fluorescence. Pavlopoulos and Hammond suggested that methylene bridged quaterphenyls such as dye 2 might prove to be superior laser dyes. ${ }^{8}$

We prepared a sample of dye 2 during 1983 and found that it lased both excimer laser and flashlamp-pumped. Dyes 2 and 3 have recently been reported as effective excimer-pumped laser dyes. ${ }^{9}$ We prepared dyes 3-8 and now report on their fluorescence and lasing properties when flashlamp-pumped.

\section{EXPERIMENTAL}

Dye 1 was obtained from Exciton Chemical Co., Inc. as "BBQ." ${ }^{\circ}$ Dye 2 was synthesized according to Wen and Kovacic. ${ }^{10}$ Dye 3 was prepared by essentially the method of Wirth et al. ${ }^{11}$ Dyes 4-8 are new compounds we made by standard methods which will be reported elsewhere. 
Solubilities of dyes at $20-23^{\circ}$ were determined either by shaking suspensions with incremental additions of solvent until the dye crystals disappeared, or by measuring the ultraviolet absorption of saturated solutions.

Ultraviolet spectra were determined with a Cary 15 spectrometer in $1 \mathrm{~cm}$ quartz cells at a concentration of $\approx 2.5 \times 10^{-5} \mathrm{M}$. The solutions used for determination of FQE were all adjusted to an absorbance of $0.1 \pm 10 \%$ using $10 \mathrm{~cm}$ quartz cells in the Cary 15 .

Fluorescence spectra were obtained with a Perkin-Elmer MPF-44A spectrometer (operated in ratio mode with Rhodamine B in the reference compartment) in conjunction with a Hitachi corrected spectra unit. Slit widths used were $1 \mathrm{~nm}$ for excitation and $3 \mathrm{~nm}$ for emission. FQEs were determined by the dilute solution method ${ }^{12}$ where the reference compound was p-terphenyl in cyclohexane, and its FQE was taken as $0.77 .{ }^{13}$ Areas of emission spectra were determined to $\pm 2 \%$ with a planimeter (Los Angeles Scientific Instrument Co. Model L 20M).

The flashlamp-pumped laser was a Phase-R Model DL-1200. The volume of the dye solution was 0.3 liters, and it was pumped at 2-3 liters/min through a $0.3 \mu$ glass filter. The rise-time of the flashlamp was $25 \mathrm{~ns}$. The output mirror had a reflectivity of $70 \%$ at wavelengths of $340-420 \mathrm{~nm}$. The energy input was determined by measuring the voltage. The energy output was found with a Laser Precision RK 3230 energy meter.

\section{DISCUSSION AND RESULTS}

Very high FQEs were reported by Berlman ${ }^{14,15,16}$ for a number of methylene- and oxygen-bridged oligophenylenes. The Stokes shift is reduced by bridging, mainly by a red-shift in the absorption spectrum, because the ground state is partially flattened out by bridging, and more nearly resembles the planar ${ }^{13,15} S_{1}$ state. For example, the $\mathrm{S}_{0} \rightarrow \mathrm{S}_{1}$ band of quaterphenyl at $293 \mathrm{~nm}^{17}$ is shifted to $323 \mathrm{~nm}$ by a single methylene bridge between rings 2 and $3 .^{15,17}$ This suggested that a lowered threshold of lasing was possible. Extreme bridging, where all the rings of oligophenylene are fused with methylene groups, causes self-absorption ${ }^{14,17}$ which might limit laser output. Also solubility would suffer since more rigid compounds tend to be less soluble. 
Accordingly 2,2'-bifluorene (2), a quaterphenyl with two methylene bridges, was prepared. It was found to lase flashlamp-pumped in either DMA, DMF or ethanol (Table III) with a lower threshold than dye 1. When pumped at $308 \mathrm{~nm}$ by a xenon chloride excimer laser, dye 2 showed $30 \%$ more output power than dye 1 . No further testing was done on dye 2 since it was thought that the susceptibility of the doubly benzylic hydrogens on its methylene bridges to oxidation and to other reactions with radicals would limit its lifetime. This was confirmed recently by Rinke et al. ${ }^{9}$ using excimer laser pumping, with which dye 2 was short-lived, showing only $8.5 \%$ the lifetime of dye 3 , which, in turn, was shorter-lived than that of some of the better unbridged quaterphenyls under similar conditions. ${ }^{4}$ In addition, the solubility of dye 2 is hardly greater than that of quaterphenyl in toluene, ${ }^{2,7}$ or that of dye 1 in DMF (Table I).

Substitution of the benzylic hydrogens was next carried out, not by methyl groups, which would have had little effect on solubility, but by propyl groups (compound 6). Now there was the possibility that a fracture during lasing of one of the bonds joining the methylene group to a benzene ring would be a source of limited photochemical lifetime,

Table II Absorbance and fluorescence characteristics of quaterphenyl dyes tested

\begin{tabular}{lllll}
\hline Dye & Solvent $^{\mathrm{a}}$ & Absorbance (epsilon) & Fluor. em. peak & FQE $^{\mathrm{b}}$ \\
\hline 1 & $\mathrm{C}^{\mathrm{c}}$ & $305 \mathrm{~nm}(54,000)$ & $363,382 \mathrm{~nm}$ & 0.77 \\
2 & $\mathrm{E}^{\mathrm{d}}$ & 320 & 372 & 0.80 \\
& $\mathrm{D}^{\mathrm{d}}$ & $323(57,500)$ & 376 & - \\
3 & $\mathrm{C}$ & $266(12,000), 323(53,500)$ & 353,369 & 0.77 \\
& $\mathrm{E}^{\mathrm{d}}$ & $319(58,400)$ & 371 & 0.75 \\
& $\mathrm{D}^{\mathrm{d}}$ & $323(55,350)$ & 375 & - \\
4 & $\mathrm{C}$ & $264(76,300), 325(48,000)$ & 371,391 & 0.58 \\
& DMF & - & 401 & 0.65 \\
5 & E & - & 397 & 0.55 \\
6 & DMF & $322(48,000)$ & 361,378 & $0.83^{\mathrm{e}}$ \\
7 & C & $331(52,500)$ & 360,378 & 0.72 \\
8 & DMF & $331(55,000)$ & 371,389 & 0.90 \\
& DMF & $334(52,500)$ & 376,394 & 0.89 \\
\hline
\end{tabular}

${ }^{\text {a }} \mathrm{C}=$ cyclohexane, $\mathrm{D}=$ dioxane, $\mathrm{DMF}=\mathrm{N}, \mathrm{N}$-dimethylformamide, $\mathrm{E}=$ ethanol

${ }^{b} \mathrm{FQE}=$ fluorescence quantum efficiency

c Berlman; ${ }^{15,17}$ corrected according to Birks ${ }^{13}$

d Rinke $^{9}$

e Estimated 
because the diradical formed would be the stable tertiary benzylic type on one side, and an unstable phenyl radical on the other side. Whether the energetically difficult cleavage of an aryl-carbon bond would prevent the fracture, or whether the entropically favored re-closure of the ring would compensate for it was not certain. In the mass spectrum of 9,9-dipropyfluorene we found a peak at $\mathrm{m} / \mathrm{e} 250$ for the molecular ion, indicating that the fluorene radical cation has appreciable stability. The base peak at $\mathrm{m} / \mathrm{e} 207$ results from loss of a propyl radical from the parent radical cation, not aryl-carbon scission. Nevertheless, the doubly oxygen-bridged compound 3 and the doubly nitrogen-bridged compound 4 were prepared to make an empirical comparison with 6 . These three compounds were selected because they all contained two bridges each in similar locations. No labile hydrogens were present on any of the bridges. Their absorption and fluorescence spectra were much alike (Table II). Their lasing behavior differed markedly, however (Table III). Dye 6 lased flashlamp pumped with a lower threshold and $5 \times$ the output energy and 5-10× the lifetime of dye 1 , and with about $2 \times$ the output energy of Dye 2 . Dye 3 barely lased at high threshold, in complete contrast to its behavior when excimer laser pumped, ${ }^{9}$ while dye 4 did not lase at all.

Table III Lasing characteristics of the quaterphenyl dyes when flashlamp pumped

\begin{tabular}{|c|c|c|c|c|c|c|}
\hline \multirow[b]{2}{*}{$\begin{array}{l}\text { Dye } \\
\text { No. }\end{array}$} & \multirow[b]{2}{*}{ Solvent ${ }^{\mathrm{a}}$} & \multirow[b]{2}{*}{ Conc. (mol/l) } & \multicolumn{4}{|c|}{ Lasing } \\
\hline & & & $\begin{array}{l}\text { Threshold } \\
(\mathrm{KeV})\end{array}$ & $\begin{array}{l}\text { Energy } \\
(\mathrm{mJ})^{\mathrm{b}}\end{array}$ & $\begin{array}{l}\text { Peak } \\
(\mathrm{nm})\end{array}$ & $\begin{array}{l}\text { Lifetime } \\
(\mathrm{KJ} / 1)^{\mathrm{c}}\end{array}$ \\
\hline 1 & DMF & $2.0 \times 10^{-4}$ & 18 & $<1$ & 386 & 3 \\
\hline \multirow[t]{2}{*}{2} & DMA & $2.0 \times 10^{-4}$ & 16 & 1 & 380 & - \\
\hline & $\mathrm{E}$ & $1.0 \times 10^{-4}$ & 15 & 1 & 381 & - \\
\hline 3 & DMF:E::1:9 & $1.25 \times 10^{-4}$ & 20 & $<1$ & 371 & - \\
\hline 4 & DMF:E::1:9 & $1.0 \times 10^{-4}$ & (24) & no lasing & - & - \\
\hline \multirow[t]{2}{*}{5} & DMA & $9.0 \times 10^{-5}$ & 15 & 2 & 380 & 30 \\
\hline & $\mathrm{E}$ & $1.0 \times 10^{-4}$ & 15 & 2 & 365 & 15 \\
\hline \multirow[t]{2}{*}{6} & DMF:E::1:9 & $1.0 \times 10^{-4}$ & 14 & 2 & 381 & 30 \\
\hline & $\mathrm{E}$ & $1.0 \times 10^{-4}$ & 14 & 2 & 381 & 15 \\
\hline \multirow[t]{2}{*}{7} & DMA:E::4:1 & $9.0 \times 10^{-5}$ & 15 & 4 & 386 & 30 \\
\hline & $\mathbf{E}$ & $8.0 \times 10^{-5}$ & 14 & 7 & 386 & 15 \\
\hline \multirow[t]{2}{*}{8} & DMA:E::4:1 & $9.0 \times 10^{-5}$ & 15 & 3 & 391 & 30 \\
\hline & $\mathrm{E}$ & $8.0 \times 10^{-5}$ & 14 & 10 & 391 & 15 \\
\hline
\end{tabular}

${ }^{a} \mathrm{DMF}=\mathrm{N}, \mathrm{N}$-dimethylformamide, $\mathrm{E}=$ ethanol, $\mathrm{DMA}=\mathrm{N}, \mathrm{N}$-dimethylacetamide

${ }^{b}$ Initial pulse energy output at optimum energy input, usually $18-22 \mathrm{KeV}$

c Total pumping energy delivered to flashlamp per liter of lasing solution until laser output energy is $50 \%$ of the initial value. 
The only other bridging element investigated was silicon. No FQEs of any 9-silafluorenes at $\approx 20^{\circ}$ were found in the literature. Davydov reported an FQE of 0.56 at $77 \mathrm{~K}$ for 9,9-diphenyl-9-silafluorene. ${ }^{18} \mathrm{We}$ thought that the FQE might become higher if alkyl groups rather than phenyl groups were attached to the silicon. While X-ray crystallographic studies have shown that fluorene is planar, ${ }^{19}$ the two phenyl rings are not aligned with each other at an "angle" of $180^{\circ}$. A line that passes through C-2 and C-4a (see dye 2, Figure 1, for numbering) makes an angle of $156^{\circ}$ with a line that passes through $\mathrm{C}-4 \mathrm{~b}$ and $\mathrm{C}-7 .{ }^{19}$ We made calculations based on obtaining maximum area for the center ring of 9-silafluorene, and these indicated a corresponding angle of $160^{\circ}$. This would indicate reduced Baeyer strain in the hetero ring, and less bending of the fluorophor along its main axis. Such an angle might have made the $S_{1}$ state of lower energy than that of fluorene, improving the FQE and lasing properties. Again using p-terphenyl in cyclohexane as a reference compound $(\mathrm{FQE}=0.77)$, we found an FQE of 0.40 for 9,9-dipropylfluorene, 0.09 for 9,9-dimethylsilafluorene, and 0.10 for 9,9-diethoxy-9-silafluorene, all in cyclohexane. Therefore, no further investigation was made of compounds with silicon bridges.

The dipropylmethylene bridges having proved the best, the next comparison was between dye 6 (two bridges), which was expected to be more soluble, and dye 5 (one bridge), which was easier to synthesize and purify. Their lasing properties were about the same, with peak emission observed near $380 \mathrm{~nm}$ in both cases, with $>2 \times$ the energy output and $5-10 \times$ the lifetime of dye 1 . Surprisingly (to us), dye 5 was more soluble than dye 6 in all four solvents in which data were obtained for both (Table I).

When a single dipropylmethylene bridge between the middle rings of quaterphenyl was found to have the better lasing and solubility properties, quaterphenyls bearing auxofluors in addition were prepared (dyes 7 and 8). These showed lasing peaks at 386 and $391 \mathrm{~nm}$,

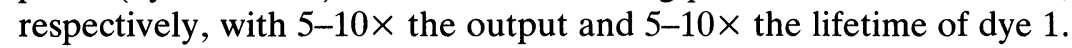
Dye 8 may be the first example of a laser dye in which a cyclic ether has been used as an auxofluor. Its absorption peak was red-shifted $3 \mathrm{~nm}$ from dye 7 , and its fluorescence and lasing peaks were red-shifted $5 \mathrm{~nm}$ from dye 7. No other properties were greatly affected.

The solvent N,N-dimethylacetamide (DMA) was substituted for $\mathrm{N}, \mathrm{N}$-dimethylformamide (DMF) in the later stages of the work, and 
appeared to be more stable under lasing conditions than DMF, as well as a better solvent than DMF for 3 of 4 of the dyes tested (Table I). Greater lifetime for coumarin dyes in DMA than in DMF has been reported. ${ }^{20}$

Dyes 7 and 8 are commercially available. ${ }^{21}$

\section{CONCLUSIONS}

For flashlamp pumping o, $\mathrm{o}^{\prime}$-bridging of rings 1 and 2 as well as rings 3 and 4 of quaterphenyl with carbon (dyes 2 and 6) gave laser dyes with superior properties to those bridged in similar positions with oxygen (dye 3), while a quaterphenyl bridged in similar positions with nitrogen (dye 4) did not lase under the conditions used. Apparently, even the tightly-held non-bonded electron pairs of oxygen and nitrogen atoms are susceptible to transitions leading to triplet state formation that interferes with lasing. ${ }^{8}$ The FQEs of a pair of 9-silafluorenes was so low compared with that of 9,9-dipropylfluorene that silicon was not investigated further as a bridging element.

Substitution of propyl groups for hydrogens on the carbon bridges gave greatly improved solubility and improved energy output (compare dyes 2 and 6). A single dipropylmethylene bridge between rings 2 and 3 was as effective as double bridging so far as lasing properties and solubility were concerned (compare dyes 5 and 6 ).

Attachment of alkoxy (ether) groups at both ends of the fluorophor (dyes 7 and 8) gave similarly long lifetime, an improvement in solubility, higher laser output, and the expected red-shifts.

\section{Acknowledgements}

Discussions with T. G. Pavlopoulos, Naval Ocean Systems Center, San Diego, CA, USA, are greatly appreciated. The excimer laser pumping data for dyes 1 and 2 were provided by R. Steppel, Exciton Chemical Co., Inc., Dayton, OH, USA. The two silafluorenes were provided by J. Y. Corey, Department of Chemistry, University of Missouri, St. Louis, MO, USA. The calculations of bond angles were carried out by A. Nijenhuis, Department of Mathematics, University of Pennsylvania, Philadelphia, PA, USA. Computer-assisted literature searches by N. B. Rainey and technical assistance from S. J. Imbesi and P. Erndwein are appreciated. Partial financial support for the work from the Phila. Co. of Phcy. \& Science Summer Faculty Research Fund is gratefully acknowledged.

\section{References}

1. M. Maeda, Laser Dyes: Properties of Organic Compounds for Dye Lasers (Academic Press, Tokyo, 1984). 
2. H. O. Wirth, K. H. Gönner, R. Stück and W. Kern, Makromol. Chem. 68, 53 (1963).

3. W. Zapka and U. Brackmann, Appl. Phys. 20, 283 (1979).

4. M. Rinke, H. Güsten and H. J. Ache, J. Phys. Chem. 90, 2661 (1986).

5. W. Hüffer, R. Schieder, H. Telle, R. Raue and W. Brinkwerth, Optics Comm. 33, 85 (1980).

6. J. M. Kauffman, Appl. Optics 19, 3431 (1980).

7. M. D. Barnett, G. H. Daub, F. N. Hayes and D. G. Ott, J. Am. Chem. Soc. 81, 4583 (1959).

8. T. G. Pavlopoulos and P. R. Hammond, J. Am. Chem. Soc. 96, 6568 (1974).

9. M. Rinke, H. Güsten and H. J. Ache, J. Phys. Chem. 90, 2666 (1986).

10. L.-S. Wen and P. Kovacic, Tetrahedron 34, 2723 (1978).

11. H. O. Wirth, G. Waese and W. Kern, Makromol. Chem. 86, 139 (1965).

12. J. N. Demas and G. A. Crosby, J. Phys. Chem. 75, 991 (1971).

13. J. B. Birks, Photophysics of Aromatic Molecules (Wiley-Interscience, London, 1970).

14. I. B. Berlman, J. Chem. Phys. 52, 5616 (1970).

15. I. B. Berlman, H. O. Wirth and O. J. Steingraber, J. Phys. Chem. 75, 318 (1971).

16. I. B. Berlman, J. Phys. Chem. 77, 562 (1973).

17. I. B. Berlman, Handbook of Fluorescence Spectra of Aromatic Molecules (Academic Press, New York, 1971) 2nd ed.

18. S. N. Davydov, A. N. Rodionov, D. N. Shigorin, O. P. Syutkina and T. L. Krasnova, Zh. Fiz. Khim. 55, 784 (1981).

19. G. M. Brown and M. H. Bortner, Acta Cryst. 7, 139 (1954).

20. A. N. Fletcher, M. W. Pietrak and D. E. Bliss, Appl. Phys. B, in press.

21. Exciton Chemical Co., Inc., P.O. Box 31126, Overlook Station, Dayton, OH 45431 . 